\title{
Spatial-temporal variations of lake ice phenology in the Hoh Xil region from 2000 to 2011
}

\author{
YAO Xiaojun ${ }^{1}$, LI Long ${ }^{1,2}$, ZHAO Jun ${ }^{1}$, SUN Meiping ${ }^{1,3}$, LI Jing ${ }^{1}$, \\ GONG Peng ${ }^{1}$, AN Lina ${ }^{1}$ \\ 1. College of Geography and Environment Sciences, Northwest Normal University, Lanzhou 730070, China; \\ 2. Lanzhou Resources \& Environment Voc-Tech College, Lanzhou 730021, China; \\ 3. State Key Laboratory of Cryosphere Sciences, Cold and Arid Regions Environmental and Engineering Re- \\ search Institute, CAS, Lanzhou 730000, China
}

\begin{abstract}
Lake ice phenology, i.e. the timing of freeze-up and break-up and the duration of the ice cover, is regarded as an important indicator of changes in regional climate. Based on the boundary data of lakes, some moderate-high resolution remote sensing datasets including MODIS and Landsat TM/ETM+ images and the meteorological data, the spatial-temporal variations of lake ice phenology in the Hoh Xil region during the period 2000-2011 were analyzed by using RS and GIS technology. And the factors affecting the lake ice phenology were also identified. Some conclusions can be drawn as follows. (1) The time of freeze-up start (FUS) and freeze-up end (FUE) of lake ice appeared in the late October-early November, mid-November - early December, respectively. The duration of lake ice freeze-up was about half a month. The time of break-up start (BUS) and break-up end (BUE) of lake ice were relatively dispersed, and appeared in the early February - early June, early May - early June, respectively. The average ice duration (ID) and the complete ice duration (CID) of lakes were 196 days and 181 days, respectively. (2) The phenology of lake ice in the Hoh Xil region changed dramatically in the last 10 years. Specifically, the FUS and FUE time of lake ice showed an increasingly delaying trend. In contrast, the BUS and BUE time of lake ice presented an advance. This led to the reduction of the ID and CID of lake. The average rates of ID and CID were $-2.21 \mathrm{~d} / \mathrm{a}$ and $-1.91 \mathrm{~d} / \mathrm{a}$, respectively. (3) The variations of phenology and evolution of lake ice were a result of local and climatic factors. The temperature, lake area, salinity and shape of the shoreline were the main factors affecting the phenology of lake ice. However, the other factors such as the thermal capacity and the geological structure of lake should not be ignored as well. (4) The spatial process of lake ice freeze-up was contrary to its break-up process. The type of lake ice extending from one side of lakeshore to the opposite side was the most in the Hoh Xil region.
\end{abstract}

Keywords: lake ice; phenology; climate change; Hoh Xil region; Tibetan Plateau

Received: 2015-09-01 Accepted: 2015-10-03

Foundation: National Natural Science Foundation of China, No.41261016; Scientific Research Project of Higher Learning Institution in Gansu Province, No.2014A-001, No.2013A-018

Author: Yao Xiaojun (1980-), PhD and Associate Professor, specialized in the research of GIS and lake evolution. E-mail: xj_yao@nwnu.edu.cn 


\section{Introduction}

Climate change is an important common subject around the world (Qin, 2012). According to the Intergovernmental Panel on Climate Change (IPCC), the average global temperature had risen by $0.89^{\circ} \mathrm{C}$ from 1951 to 2012 and showed a significant accelerated rising trend (Vaughan et al., 2013). There is a strong link between climate change and lake ice phenology (Benson et al., 2012; Kropáček et al., 2013; Zhang et al., 2015). Experience and model studies have indicated that the freeze-up duration and the break-up duration of lake ice are closely associated with the temperature change (Deguay et al., 2006). Analysis of ice phenology of numerous lakes in the Northern Hemisphere showed that a $1{ }^{\circ} \mathrm{C}$ rise in mean air temperature corresponds to a reduction of 4-7 days in the duration of the ice cover season (Palecki and Barry, 1986).Thus, lake ice phenology is recognized and established as a tangible and technically feasible indicator of local climate change; it is used to support climate change research at all scales from local to global (Hodgkins et al., 2002; Gould and Jeffries, 2005; Johnson and Stefan, 2006; Marszelewski and Skowron, 2006; Qin, 2012; Vaughan et al., 2013). Despite recognizing the importance of lake ice monitoring, observations of lake ice freeze-up, break-up and ice thickness have dramatically declined. Costs involved in making observations as well as safety concerns for observers are suggested for the reduction (Lenormand et al., 2002).

Encouragingly, satellite remote sensing provides an alternative means to collect observations of lake ice phenology and has been used widely in North America and Europe (Hall and Riggs, 2002; Latifovic and Pouliot, 2007). For instance, Wang et al. (2012) found that there had been a significant downward trend in lake ice cover over the Great Lakes in North America over the 1973-2010 period based on AVHRR, GOES and MODIS satellite imagery. Benson et al. (2012) reported that ice phenology of 75 lakes in North America changed rapidly in the last 30 years, and the freeze-up and break-up of lake ice had a delay of $1.6 \mathrm{~d} / 10 \mathrm{a}$ and an advance of $1.9 \mathrm{~d} / 10 \mathrm{a}$, respectively. They suggested that the freeze-up duration of lake ice was closely related to temperature in autumn, winter and spring. Comparatively, the study on ice phenology of lakes in China is seldom. Qinghai Lake and Nam Co are the few special cases. Che et al. (2009) established a complete sequence of Qinghai Lake ice phenology from 1978 to 2006 based on SSM/I data and found that the ice cover duration reduced by 14-15 days. The average freeze-up duration of Nam Co was 90 days and the timing of freeze-up and break-up happened in February and May, respectively (Qu et al., 2012). Experiments conducted in Nam Co showed that MODIS imagery could provide an accurate judgment on the timing of lake ice break-up start while AMSR-E did well in identifying the timing of lake ice freeze-up end and break-up end (Wei and Ye, 2010).

The Tibetan Plateau (TP) was identified as one of the most sensitive regions in the world to changes in climate because of its unique properties (Wu et al., 2005). The Hoh Xil region located in the hinterland of the TP spans the Yangtze River and the TP inland lake basins and includes numerous lakes (Figure 1). Most of the lakes are brackish or semi-brackish in the Hoh Xil region. Freshwater lakes and salt lakes are less distributed. There are 83 lakes with area more than 10 $\mathrm{km}^{2}$ each and the total area is about $7747 \mathrm{~km}^{2}$ in the Hoh Xil region (Yao et al., 2014). The lakes have been expanding quickly since the early 1990s and some lakes (e.g. Huiten Nor and Hoh Sai Lake) spilled because of increased precipitation (Yao et al., 2012). Due to the hostile natural conditions and wildlife refuge establishment, the lakes in the Hoh Xil region are seldom influenced by human activities and remain in their naturally state. Therefore, studies on lakes in 
the Hoh Xil region can not only fill the lack of ice phenology on the TP, but also promote a deeper understanding of the TP's climate change. In this study, the objective is to clarify the spatial-temporal variations of lake ice phenology in the Hoh Xil region based on long time series of remote sensing imagery.

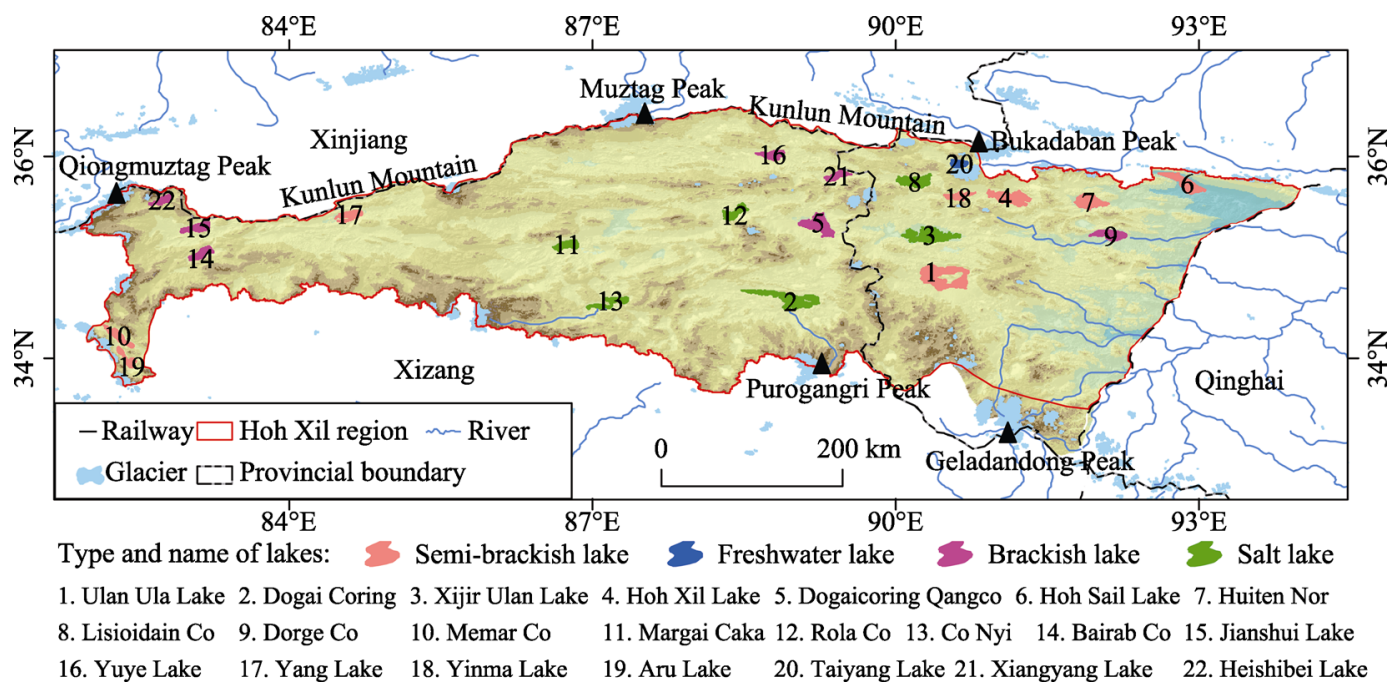

Figure 1 Names and locations for lakes analyzed in the Hoh Xil region

\section{Data and methods}

\section{$2.1 \quad$ Selected lakes}

All the 83 lakes had an area larger than $10 \mathrm{~km}^{2}$ each in the Hoh Xil region, of which 22 lakes greater than $100 \mathrm{~km}^{2}$ were selected as the studying objects. These lakes are distributed evenly in the study area. Figure 1 shows the geographical location of the lakes analyzed. The vector representation of 22 lakes was extracted from the Landsat TM/ETM+ imagery (Yao et al., 2014). The properties of lakes including the elevation and salinity were from the monograph of Records of Lakes in China (Wang and Dou, 1998).

\subsection{Satellite data}

In order to accurately obtain the timing of formation and decay of ice cover over lakes, MODIS MOD09GA data products with high temporal resolution (1 day) and moderate spatial resolution ( $250 \mathrm{~m}$ on bands 1 and 2, $500 \mathrm{~m}$ on bands 3 and 4) were adopted. In total 2816 scenes of MODIS MOD09GA from 2000 to 2011 with a storage of about 250 GB were used in this study and were downloaded from the website (http://www.gscloud.cn) of Computer Network Information Center, Chinese Academy of Sciences. Ground observations of lake ice phenology in the remote Hoh Xil region with harsh winter conditions are not available. As an alternative, 891 scenes of Landsat TM/ETM+ imagery with a spatial resolution of $30 \mathrm{~m}$ provided by the USGS/NASA (http://earthexplorer.usgs.gov) were processed to verify the accuracy of the lake ice phenology extracted from the MODIS MOD09GA data.

\subsection{Meteorological data}

Although there are only three national meteorological stations of Wudaoliang, Gerze and 
Shiquanhe around the Hoh Xil region, it is doubt that the observations from these stations can denote the meteorological conditions around the lakes due to the far distance. We used $0.5^{\circ} \times 0.5^{\circ}$ temperature grid data which was generated from observation data of all national meteorological stations and GTOPO30 DEM. This dataset was provided by the Chinese Meteorological Science Data Center (http://cdc.cma.gov.cn). The temperature of lakes was extracted from the neighbor grids.

\subsection{Automated extraction of lake ice}

Lake ice information is usually extracted by ground observing and remote sensing monitoring. The former is high-precision, but time-consuming and laborious. On the contrary, remote sensing monitoring method has a larger range of observation and a higher update speed. The remote sensing identification of lake ice is on the basis of the spectral characteristic of ice and water, mainly including artificial visual interpretation method, threshold method and index method (Reed et al., 2009; Choinski et al., 2010; Wei and Ye, 2010). The first method is usually laborious and needs rich experience and expertise. The index method distinguishes ice from water by band calculation. The threshold method synthetically considers the reflectivity, temperature, backward scattering coefficient and other characteristics of ice and water of the lakes. So it can provide a higher precision result and is widely applied. The threshold method was represented as follows:

$$
\text { result }=\left\{\begin{array}{l}
\text { lake ice, if } \rho_{\text {red }}-\rho_{N I R}>a \text { and } \rho_{\text {red }}>b \\
\text { no-lake ice, if } \rho_{\text {red }}-\rho_{N I R}<a \text { or } \rho_{\text {red }}<b
\end{array}\right.
$$

where $\rho_{\text {red }}$ and $\rho_{\text {NIR }}$ denote the reflectance of red band and near-infrared band, respectively. They are corresponding to Band 1 and Band 2 of MODIS MOD09GA data. Two thresholds $(a$ and $b$ ) are used to distinguish the lake ice from water body and are assigned to 0.02 and 0.05 proposed by Wei and Ye (2010).

Figure 2 shows the Hoh Sai Lake status in Landsat TM and MODIS imagery on November 28,2001 . The area of ice cover was $175.41 \mathrm{~km}^{2}$ based on the artificial visual interpretation of Landsat TM imagery (see Figure 2a). It was $178.01 \mathrm{~km}^{2}$ extracted from the threshold method applying to MODIS MOD09GA data. The difference was $2.61 \mathrm{~km}^{2}(1.48 \%)$ indicating that the threshold method performed much better.
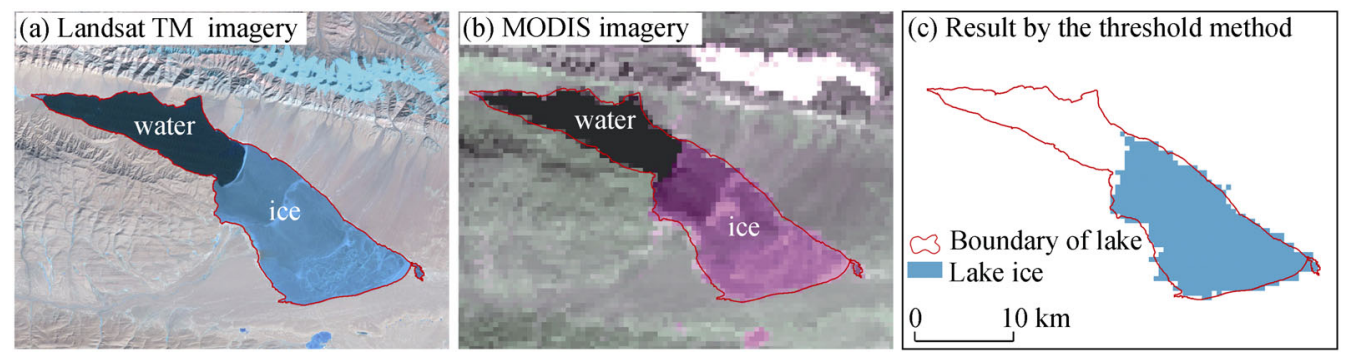

Figure 2 The status of the ice cover of the Hoh Sail Lake on November 28, 2001

\subsection{Automated identification of lake ice phenology}

The lake ice phenology deals with periodic formation and decay of ice cover over lake water bodies and changes in timing as a result of seasonal and inter-annual variations in climate 
(Kropáček et al., 2013). It is characterized with the following four events in the profile: 1) ice break-up start (BUS), 2) ice break-up end (BUE), 3) freeze-up start (FUS) and freeze-up end (FUE). Freeze-up date is defined to occur when ice cover is $\geq 90 \%$ of the lake area; break-up date is when ice cover is $\leq 10 \%$ (Reed et al., 2009). Therefore, the parameters of lake ice phenology can be automatically extracted by the calculation as below:

$$
\text { result }=\left\{\begin{array}{l}
F U S, \text { if } I A \geqslant 0.1^{*} L A \\
F U E, \text { if } I A \geqslant 0.9^{*} L A \\
B U S, \text { if } I A \leqslant 0.9^{*} L A \\
B U E, \text { if } I A \leqslant 0.1^{*} L A
\end{array}\right.
$$

where $I A$ and $L A$ refer to the ice area and lake area, respectively. The value of $I A$ can be calculated based on the automated extraction of the lake ice mentioned in section 2.4 in the GIS software. The value of $L A$ is from the result of Yao et al. (2014).

Since there are discrepancies in the definition of variables describing the duration of lake ice cover, a comparison of ice phenology records for different regions is often biased. For instance, Reed et al. (2009) defined ice duration (ID) as the time interval from FUE to BUE, while Kropáček et al. (2013) thought ID as the duration from FUS to BUE and put forward a new variable: complete ice duration (CID) meaning the time interval from FUE to BUS. The CID was the same as the freeze-up days of the Qinghai Lake in the researches by Chen et al. (1995) and Che et al. (2009). Here we use ID and CID to describe the ice duration of lakes in the Hoh Xil region.

\section{Results and discussion}

\subsection{The temporal characteristics of lake ice phenology}

The lake ice phenology for 22 lakes during 2000-2010 from MODIS data in the Hoh Xil region was given in Table 1. It is evident that the occurring date of lakes'FUS are relatively concentrated, mainly appearing in late October and early November. Among all 22 lakes, the FUS date of Yuye Lake came earliest on October 9 (the 283rd day) and that of Lisioidain Co came latest on November 14 (the 319th day). The FUS duration was within one week except for Dogai Coring and Dogaicoring Qangco. The time of lakes' FUE appeared in the period of mid-November and early December. The FUE came earliest in Yuye Lake (on October 30, the 304th day) and latest in Dogai Coring (on December 18, the 353rd day). Similarly, the FUE duration of most lakes fluctuated within one week. It was the exception for Xijir Ulan Lake and Dogaicoring Qangco which were more than half a month. The average duration from FUS to FUE of lakes was about 17 days. Only for Xijir Ulan Lake and Dogai Coring, their freeze-up duration was more than 40 days and fluctuated suddenly. For instance, the ice expansion of Xijir Ulan Lake lasted 104 days in 2004 while 21 days in 2009.

Comparatively, the date of lakes' BUS in the Hoh Xil region was disperse, beginning in early February (Xijir Ulan Lake on the 34th day) until early June (Hoh Xil Lake on the 161st day). However the BUS time of about $4 / 5$ of the lakes appeared in mid-April to early June. Except for Xijir Ulan Lake and Dogai Coring having a short CID (49 days and 72 days, respectively), the duration of complete ice cover for other lakes was about 180 days. It meant that the lakes were completely covered by ice for about half a year in the Hoh Xil region. 
The time of lakes' BUE mainly appeared in early May to early June. The BUE date of Dogai Coring came earliest in late April (on the 112nd, April 21) and that of Hoh Xil Lake came latest in late June (on the 174th day, June 22). During the study period, the average ID of lakes was 196 days in the Hoh Xil region. Dogain Coring had a shortest ID (124 days) while Yuye Lake had the longest one (227 days). However, there were inevitably extreme cases in different years. For instance, the ID of Dogaicoring Qangco was only 55 days in 2000-2001 but was as long as 191 days in 2002-2003. As for the range of ID's variations, Xiangyang Lake was the minimum (14 days) and Dogaicoring Qangco was the maximum (136 days).

Table 1 The ice phenology of lakes in the Hoh Xil region

\begin{tabular}{|c|c|c|c|c|c|c|c|c|}
\hline \multicolumn{3}{|c|}{ Lake } & \multicolumn{6}{|c|}{ Lake ice phenology } \\
\hline Name & $\begin{array}{c}\text { Area } \\
\left(\mathrm{km}^{2}\right)\end{array}$ & $\begin{array}{c}\text { Elevation } \\
\text { (m a.s.1.) }\end{array}$ & FUS & FUE & BUS & BUE & $\begin{array}{c}\text { CID } \\
\text { (days) }\end{array}$ & $\begin{array}{c}\text { ID } \\
\text { (days) }\end{array}$ \\
\hline Ulan Ula Lake & 563.79 & 4854 & $297 \pm 2$ & $321 \pm 4$ & $116 \pm 23$ & $164 \pm 8$ & $160 \pm 23$ & $208 \pm 11$ \\
\hline Dogai Coring & 459.62 & 4921 & $308 \pm 16$ & $353 \pm 8$ & $61 \pm 8$ & $112 \pm 15$ & $72 \pm 11$ & $124 \pm 20$ \\
\hline Xijir Ulan Lake & 395.95 & 4769 & $301 \pm 8$ & $350 \pm 18$ & $34 \pm 23$ & $127 \pm 15$ & $49 \pm 33$ & $142 \pm 19$ \\
\hline Hoh Xil Lake & 319.43 & 4878 & $300 \pm 3$ & $318 \pm 3$ & $161 \pm 4$ & $174 \pm 6$ & $208 \pm 4$ & $221 \pm 7$ \\
\hline Dogaicoring Qangco & 313.08 & 4787 & $310 \pm 13$ & $327 \pm 17$ & $107 \pm 31$ & $124 \pm 24$ & $146 \pm 49$ & $163 \pm 42$ \\
\hline Hoh Sail Lake & 268.01 & 4475 & $318 \pm 2$ & $337 \pm 3$ & $129 \pm 5$ & $141 \pm 8$ & $157 \pm 6$ & $169 \pm 9$ \\
\hline Huiten Nor & 261.32 & 4751 & $312 \pm 5$ & $326 \pm 2$ & $146 \pm 6$ & $160 \pm 7$ & $185 \pm 7$ & $198 \pm 9$ \\
\hline Lisioidain Co & 246.27 & 4867 & $319 \pm 6$ & $334 \pm 6$ & $109 \pm 17$ & $126 \pm 12$ & $140 \pm 22$ & $158 \pm 18$ \\
\hline Dorge Co & 205.33 & 4688 & $300 \pm 7$ & $310 \pm 8$ & $116 \pm 13$ & $147 \pm 9$ & $171 \pm 16$ & $202 \pm 14$ \\
\hline Memar Co & 147.77 & 4920 & $304 \pm 5$ & $322 \pm 5$ & $145 \pm 6$ & $167 \pm 8$ & $188 \pm 10$ & $210 \pm 11$ \\
\hline MargaiCaka & 144.19 & 4785 & $300 \pm 6$ & $310 \pm 5$ & $137 \pm 7$ & $153 \pm 8$ & $192 \pm 10$ & $208 \pm 12$ \\
\hline Rola Co & 142.63 & 4807 & $293 \pm 6$ & $311 \pm 3$ & $128 \pm 8$ & $150 \pm 9$ & $182 \pm 9$ & $204 \pm 11$ \\
\hline Co Nyi & 137.73 & 4902 & $296 \pm 3$ & $315 \pm 6$ & $121 \pm 16$ & $160 \pm 6$ & $171 \pm 20$ & $210 \pm 11$ \\
\hline Bairab Co & 136.25 & 4958 & $302 \pm 7$ & $319 \pm 5$ & $152 \pm 8$ & $167 \pm 8$ & $197 \pm 11$ & $212 \pm 11$ \\
\hline Jianshui Lake & 129.65 & 4884 & $291 \pm 4$ & $307 \pm 4$ & $146 \pm 8$ & $161 \pm 9$ & $204 \pm 11$ & $219 \pm 12$ \\
\hline Yuye Lake & 120.16 & 4850 & $283 \pm 2$ & $304 \pm 7$ & $153 \pm 15$ & $166 \pm 12$ & $214 \pm 18$ & $227 \pm 16$ \\
\hline Yang Lake & 118.12 & 4778 & $296 \pm 3$ & $315 \pm 6$ & $148 \pm 5$ & $161 \pm 4$ & $198 \pm 10$ & $210 \pm 9$ \\
\hline Yinma Lake & 107.41 & 4918 & $289 \pm 2$ & $311 \pm 2$ & $135 \pm 19$ & $166 \pm 8$ & $189 \pm 20$ & $220 \pm 10$ \\
\hline Aru Co & 105.16 & 4940 & $313 \pm 5$ & $331 \pm 6$ & $81 \pm 17$ & $134 \pm 12$ & $115 \pm 15$ & $168 \pm 13$ \\
\hline Taiyang Lake & 101.91 & 4882 & $316 \pm 4$ & $329 \pm 3$ & $145 \pm 11$ & $164 \pm 9$ & $181 \pm 13$ & $201 \pm 10$ \\
\hline Xiangyang Lake & 100.58 & 4870 & $300 \pm 4$ & $310 \pm 3$ & $150 \pm 7$ & $162 \pm 2$ & $205 \pm 9$ & $217 \pm 5$ \\
\hline Heishibei Lake & 100.55 & 5048 & $301 \pm 6$ & $317 \pm 5$ & $159 \pm 3$ & $169 \pm 4$ & $207 \pm 4$ & $217 \pm 6$ \\
\hline
\end{tabular}

\subsection{The spatial characteristics of lake ice freeze-up and break-up}

The spatial pattern of ice freeze-up and break-up can reflect the differences in depth and salinity of the lakes. Qinghai Lake and Nam Co begin to freeze up from the shallow water along the shoreline and gradually expand to the deep-water area (Che et al., 2009, Qu et al., 2012). The process of ice freeze-up and break-up of lakes in the Hoh Xil region presented obvious differences because of their complex shape and geological structure. Figure 3 shows the phases of ice freezing and melting of Hoh Sail Lake, Dorge Co and Ulan Ula Lake. For 
Hoh Sail Lake, it is apparent that ice firstly emerged on the southeast bank and then gradually extended to the northeast until covering the entire lake. Instead, the lake ice firstly formed on the northwest bank, then grew around the bank and extended into the central area on the Dorge Co water surface. The freeze-up process of Ulan Ula Lake was more complicated. The Ulan Ula Lake was composed of three parts blocked by Zhenghuridge. As shown in Figure 3, the southern part of Ulan Ula Lake was firstly covered by ice, followed by the northern part, and finally the eastern part. Moreover, the ice formed earlier at the joints area where lake was connected by the narrow waterway. Although the freeze-up process of three lakes was different, an obvious feature was that the spatial pattern of lake ice break-up was opposite to its freeze-up process. In other words, it was relatively late to break up in where lake ice formed earlier and vice versa.

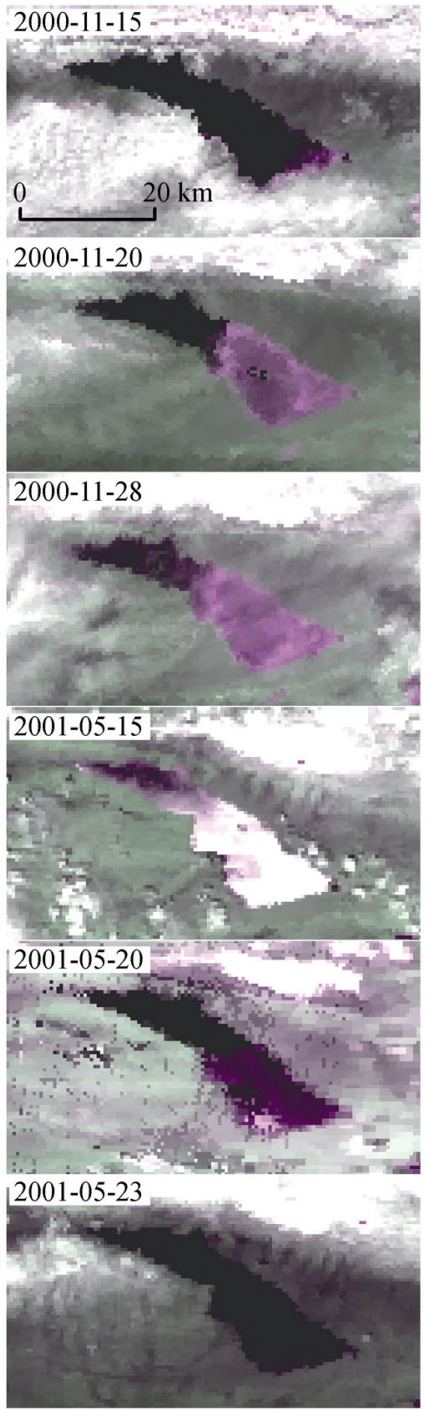

Hoh Sail Lake
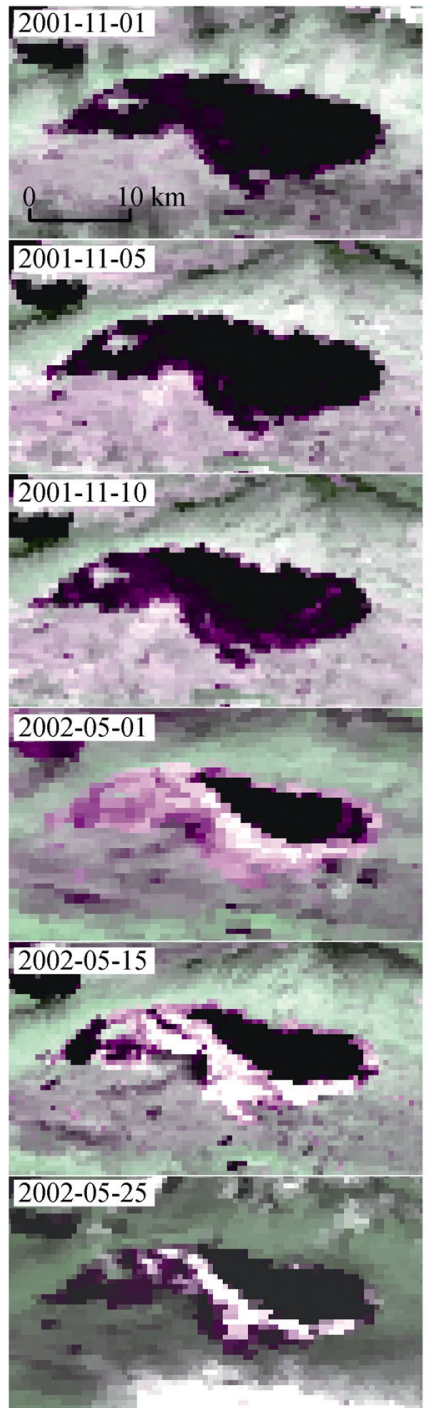

Dorge Co
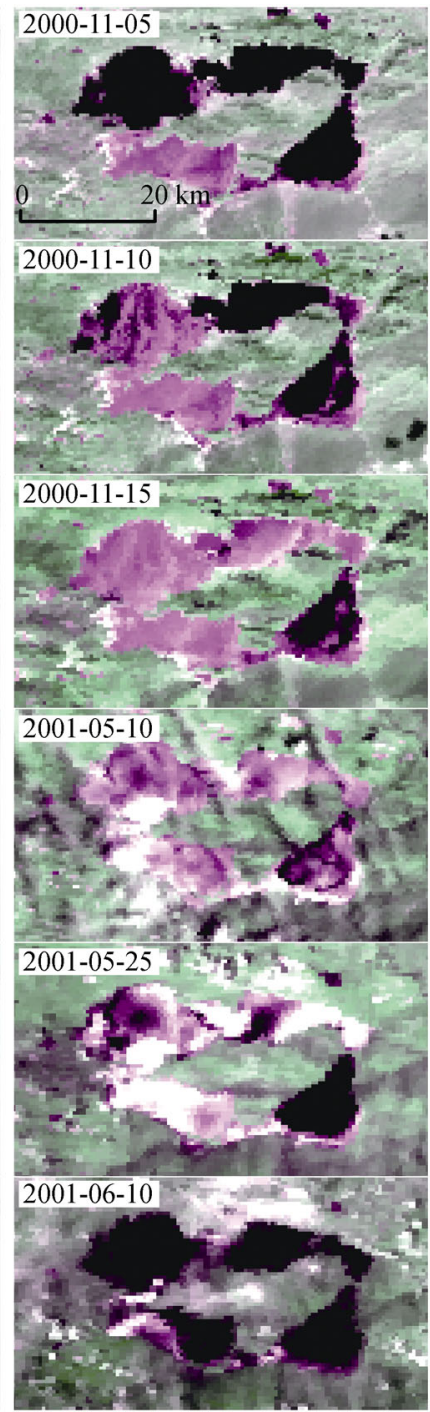

Ulan Ula Lake

Figure 3 The process of lake ice freezing and melting (the purple or white region denotes lake ice and the black region represents lake water) 
After inspecting the freeze-up process of these 22 lakes in the Hoh Xil region, we found that the spatial patterns of lake ice freeze-up could be classified into three types (Figure 4): 1) lake ice extending from one bank to the opposite side; 2) lake ice extending around the shoreline to the center of lake; 3) lake ice firstly emerging in sub-lake then expanding to the whole lake. Of the 22 lakes in the Hoh Xil region, 11 lakes belonged to the first type, followed by the second type (7 lakes). The third type only included four lakes of Ulan Ula Lake, Dogai Coring, Xijir Ulan Lake and Co Nyi. The spatial pattern of lake ice freeze-up was not only related to its shape but also had a possible relationship with its lakebed landform. In the case of Hoh Sail Lake, the studies of Luo et al. (2010) demonstrated that its bed inclined from southeast to northwest, meaning deeper water occurred in the northwestern part and narrow water in the southeastern. According to the spatial pattern of ice evolution, Hoh Sail Lake firstly froze up in the shallow area and gradually extending to the deep-water area. That is to say, the spatial pattern of lake freeze-up had a good consistency with the depth of a lake.

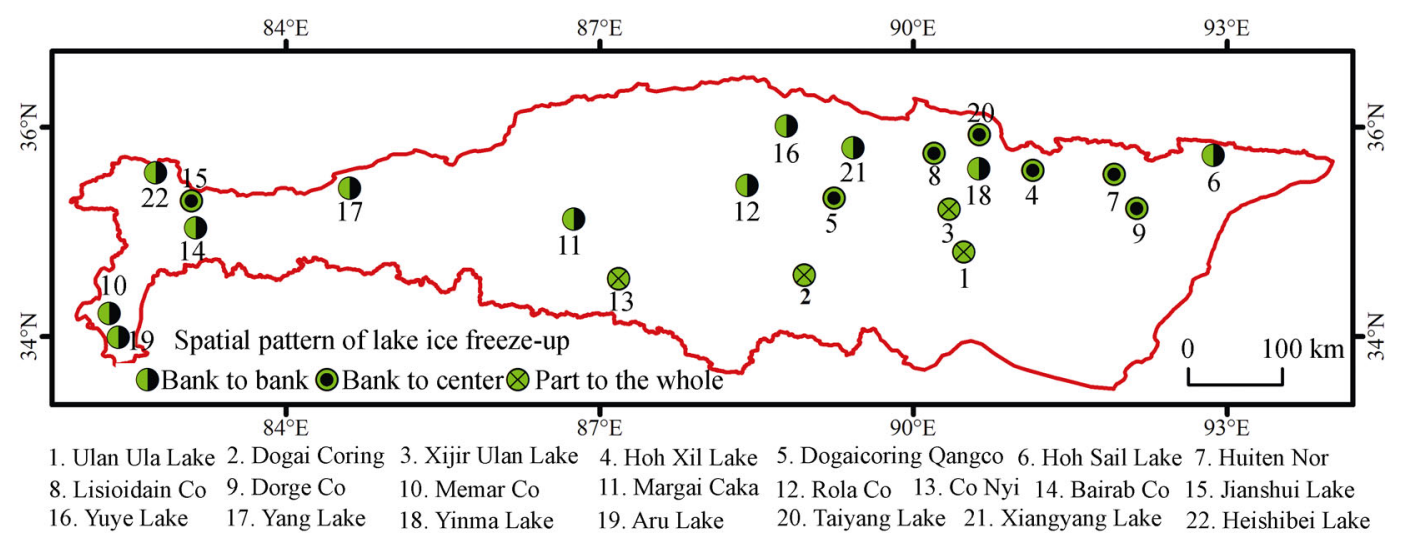

Figure 4 The spatial pattern of lake ice freeze-up in the Hoh Xil region

\subsection{Changing trend of lake ice phenology}

The phenology of lake ice had changed dramatically during the period of 2000 to 2011 in the Hoh Xil region (Figure 5). The FUS date of 20 lakes was delayed at an average rate of 0.73

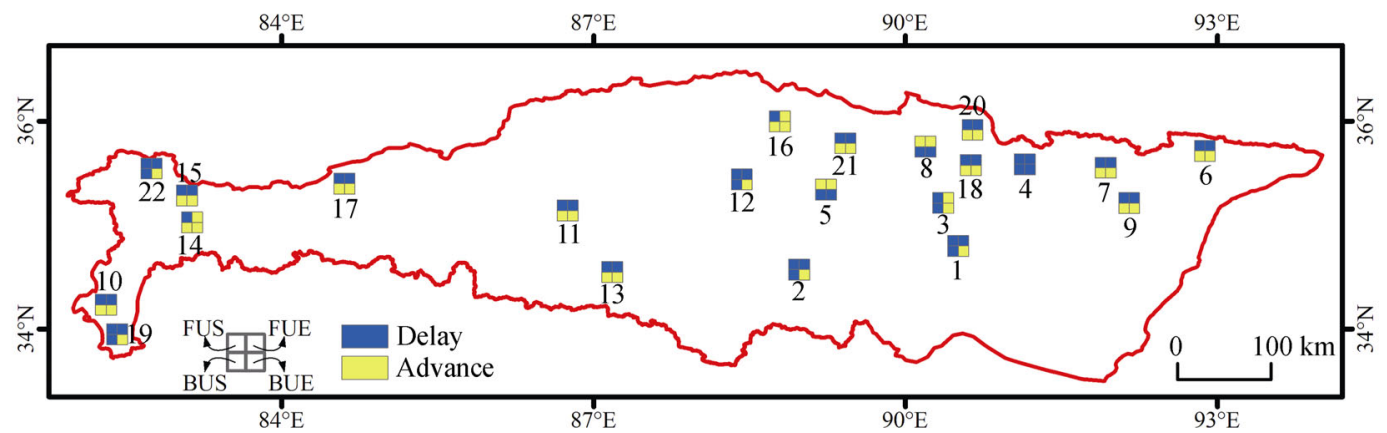

1. Ulan Ula Lake 2. Dogai Coring 3. Xijir Ulan Lake 4. Hoh Xil Lake 5. Dogaicoring Qangco 6. Hoh Sail Lake 7. Huiten Nor

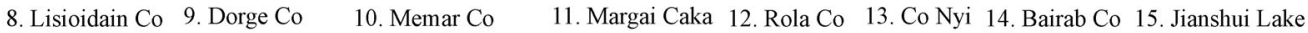

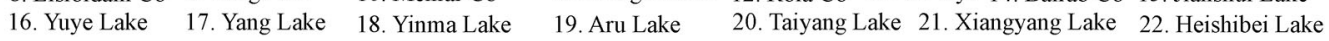

Figure 5 The variation trend of ice phenology of lakes in the Hoh Xil region from 2000 to 2011 
d/a except for Lisioidain Co and Dogaicoring Qangco. Similarly, the FUE date of 18 lakes also presented a delayed trend at a rate of $0.34 \mathrm{~d} / \mathrm{a}$. The lakes showing an advance trend of the FUE date were Xijir Ulan, Dogaicoring Qangco, Lisioidain Co and Yuye Lake located in the middle of the study area. Although the FUS and FUE time of lakes was delayed, the freeze-up duration of most lakes had been reduced at a rate of $0.39 \mathrm{~d} / \mathrm{a}$, with exception of Co Nyi and Yang Lake, being at a rate of $1.11 \mathrm{~d} / \mathrm{a}$ and $1.14 \mathrm{~d} / \mathrm{a}$, respectively.

The variations of lakes' BUS date were relatively complex in the Hoh Xil region. The BUS time showed a trend of advance in 13 lakes $(1.66 \mathrm{~d} / \mathrm{a})$ and a trend of delay in 9 lakes (3.26 d/a). Except for Aru Co and Heishibei Lake, other 7 lakes were in the middle of the Hoh Xil region. The variations of lakes' BUE date showed an obvious advanced trend. Specifically, a total of 19 lakes represented an advance of BUE date at a rate of $0.81 \mathrm{~d} / \mathrm{a}$. Only three lakes including Xijir Ulan, Hoh Xil Lake and Yuye Lake showed a slight delay of BUE date. Due to the FUE delay and the BUS advance, the CID of 14 lakes had been reduced at an average rate of $2.21 \mathrm{~d} / \mathrm{a}$. Compared with Qinghai Lake (at a rate of $-0.52 \mathrm{~d} / \mathrm{a}$ ), the variations of lakes' CID in the Hoh Xil region were more significant. Except for Lisioidain Co and Dogaicoring Qangco, other 20 lakes with an area more than $100 \mathrm{~km}^{2}$ each also showed a reduction in ID at an average rate of $1.91 \mathrm{~d} / \mathrm{a}$ in the Hoh Xil region.

\subsection{Analysis on factors influencing ice conditions in lakes of the Hoh Xil region}

The phenology of lake ice is not only affected by regional climate factors including temperature, wind speed, solar radiation and snow cover, but also related to the lake itself, such as the bathymetry, salinity, altitude, shape of the shoreline, area and thermal capacity of lake (Ménard et al., 2002; Barrie et al., 2006; Ghanbari et al., 2009). Air temperature has been suggested to be the most significant factor influencing the ice phenology, for instance by Livingstone (1997) and Kropáček et al. (2013). Being limited by the data available, this study was only focused on the relation of ice phenology to few factors: mean temperature, lake area, altitude, salinity and shape of the shoreline. The data of lake altitude and salinity were from $R e$ cords of Lakes in China (Wang and Dou, 1998). The mean temperature of the lakes was extracted from the neighbor grids in the $0.5^{\circ} \times 0.5^{\circ}$ temperature interpolated data set. The shape of shoreline was defined as a ratio between perimeter and area suggested by Kropáček et al. (2013). This shape index and lake area could be easily retrieved from the GIS layer of lakes.

Table 2 provides the correlation statistics between lake ice phenology and local and climatic factors. Results of the analysis showed that there was a high negative correlation between the FUS and the shoreline shape. This indicates that the shape complexity significantly affects the ice phenology, in particular, the freeze-up process providing shallow bays for the development of early ice. And along with the longer freeze-up duration, the thickness of lake ice is much greater in areas where the earlier ice emerges (Chen et al., 1995). Lake area and salinity are key factors influencing the FUE time. Generally, the larger area of a lake implies a greater volume which can enhance vertical heat transfer, reduce water evaporation and heat consumption by water dynamics. The greater thermal capacity of a larger lake will lead to slower freeze-up process. The high salinity of the lakes means lower freeze-up temperature, which is as low as $-2^{\circ} \mathrm{C}$ for salt lakes (Zheng et al., 1989). The main factors affecting lakes' BUS and BUE are lake area, salinity and air temperature and there is a negative correlation among them. In other words, the greater area, higher salinity and air temperature of the lakes will accelerate the thawing 
of ice. Lake area and temperature have an effect on the CID and ID of the lakes. But the salinity of a lake is only associated with its ice duration. The analysis revealed much higher dependency of ice phenology on mean temperature, lake area, salinity and shape of the shoreline and each factor played a different role in the process of lake ice freeze-up and break-up cycle. Unlike the opinion of Kropáček et al. (2013), altitude is not a key factor affecting the lake ice phenology in the Hoh Xil region. This could have been likely caused by the lower differences of altitudes among most lakes.

Table 2 Correlationof lake ice phenology and local and climatic factors ${ }^{*}$

\begin{tabular}{cccccc}
\hline Lake ice phenology & Lake area & Lake shape index & Altitude & Salinity & Annual temperature \\
\hline FUS & 0.22 & $-0.72^{* *}$ & -0.24 & 0.03 & 0.26 \\
FUE & $0.59^{* *}$ & -0.28 & -0.15 & $0.55^{* *}$ & $0.49^{*}$ \\
BUS & $-0.53^{* *}$ & -0.03 & 0.12 & $-0.65^{* *}$ & $-0.69^{* *}$ \\
BUE & $-0.43^{*}$ & 0.18 & 0.28 & $-0.62^{* *}$ & $-0.61^{* *}$ \\
CID & $-0.58^{* *}$ & -0.25 & 0.26 & -0.04 & $-0.75^{* *}$ \\
ID & $-0.53^{* *}$ & 0.24 & 0.24 & $-0.63^{* *}$ & $-0.60^{* *}$ \\
\hline
\end{tabular}

Note: $* *$ and $*$ represent confidence (P value) at the level of 0.01 and 0.05 , respectively.

\subsection{Complexity of lake ice conditions}

Some interesting phenomenon had been found when we examined ice cover evolution of lakes based on remote sensing imagery. For instance, Xijir Ulan Lake did not freeze up in December 2000 to January 2001 which was confirmed by the high resolution Landsat TM/ETM+ images (Figure 6). As shown in Table 1, the average CID of Xijir Ulan Lake was 49 days but had a great inter-annual fluctuation (33 days). It indicated that the ice phenology of Xijir Ulan Lake was not only affected by regional climate change but also was closely related to its own conditions. Xijir Ulan Lake was $\mathrm{MgSO}_{4}$-type with a high salinity of $256.73 \mathrm{~g} / \mathrm{L}$ and the content of $\mathrm{Na}^{+}$and $\mathrm{Cl}^{-}$being up to $92.98 \mathrm{~g} / \mathrm{L}$ and $152.37 \mathrm{~g} / \mathrm{L}$, respectively (Wang and Dou, 1998). This might be the main cause resulting in the shorter CID of Xijir Ulan Lake and even no ice cover in some years.

The other fascinating thing was that lakes spatially adjacent to each other had obvious differences in their ice cover conditions, such as Memar Co and Aru Co, Xijir Ulan Lake and Ulan Ula Lake (Figure 7). Memar Co (4920 m a.s.1.) is located at the north of Aru Co (4940 $\mathrm{m}$ a.s.1.). The water of the latter runs into the former by channel. As it is revealed in Figure 7, Memar Co was almost completely covered by ice on May 20, 2009 while Aru Co was fully melting. Owing to the approximate regional climate, the ice cover of Memar Co with larger area and higher salinity was theoretically easier to melt than Aru Co. The confusing reality made us suspect that the average water depth of Aru Co was greater than Memar Co. Thus the Aru Co with greater volume and thermal capacity began to thaw early. It suggested that the lake with a large area did not always have a large volume and thermal capacity. However this inference should be verified by the field work. Similarly, Xijir Ulan Lake and Ulan Ula Lake being spatially near each other were also melting and completely covered by ice on April 18, 2007. Both the area and water depth of the latter was greater than the former. The fact was Xijir Ulan Lake broke up in advance, which was most possibly caused by their huge difference in salinity. As mentioned in Records of Lakes in China (Wang and Dou, 1998), the 

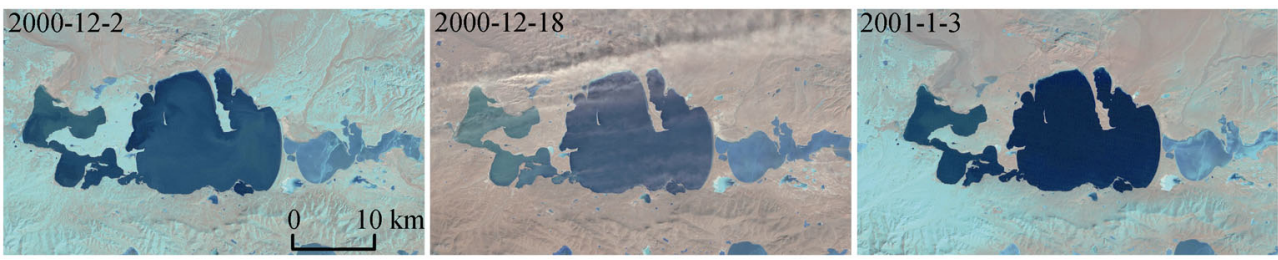

Figure 6 The status of Xijir Ulan Lake in the winter during 2000-2001

salinity of Xijir Ulan Lake was as high as $256.73 \mathrm{~g} / \mathrm{L}$ while that of Ulan Ula was only $10.92 \mathrm{~g} / \mathrm{L}$.

Co Nyi located in a fault basin of Nyima County was also a special case. It consists of eastern and western parts which are connected by a narrow waterway. As it is revealed in Figure 8, it was not frozen at the center of the joint and lake ice was gradually thawing towards the east in a fan shape. The previous field investigation found the vertical water temperature of Co Nyi presented an "S-shaped" pattern (Wang and Dou, 1998). In particular, the water temperature was gradually dropping at the depth of $0-15 \mathrm{~m}$ but rising under $15 \mathrm{~m}$ and going up to $16.3-17.3^{\circ} \mathrm{C}$ at $30-35 \mathrm{~m}$, and thus it was believed that there was a hot spring in the bottom. Hence the hot spring should lie at east portion of the joint of Co Nyi, and it also sug-

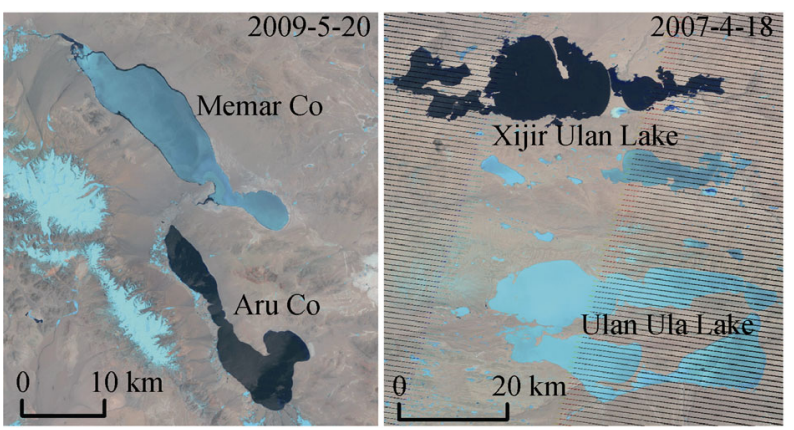

Figure 7 The ice cover of adjacent lakes in the Hoh Xil region

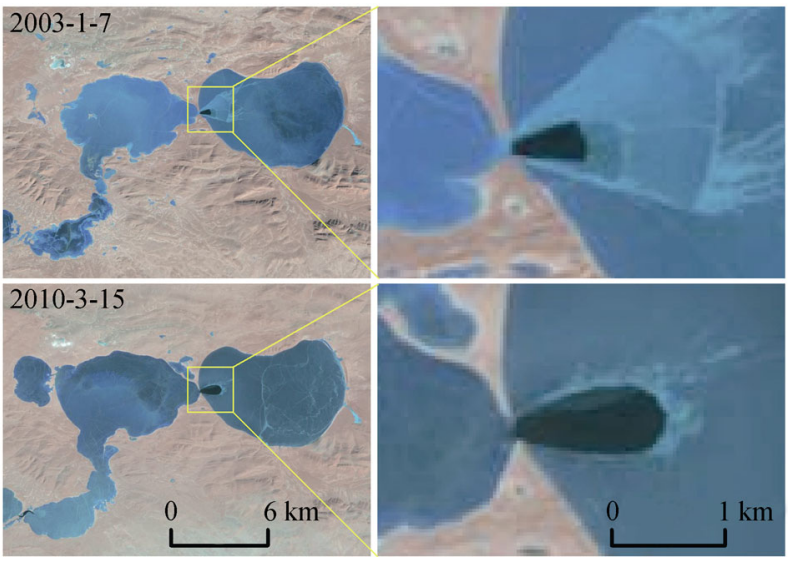

Figure 8 The ice cover of Co Nyi gested that the regional geothermal activity played an import role in the spatial evolution of lake ice.

\section{Conclusions}

In this paper, we studied the spatial-temporal variations of ice phenology of 22 lakes with area more than $100 \mathrm{~km}^{2}$ each in the Hoh Xil region during the period 2000-2011.

(1) The time of FUS and FUE of lake ice mainly appeared in the late October to early November and mid-November to early December, respectively. The duration from FUS to FUE was about half a month. The time of BUS and BUE of lake ice was relatively disperse and appeared in the early February to early June and early May to early June. The complete ice duration and average ice duration was 181 days and 196 days, respectively.

(2) The spatial process of lake ice freeze-up was contrary to its break-up process, and the 
spatial pattern of lake ice inter-annual cycle was well consistent with its bottom landform. There were three types of lake ice freeze-up and break-up spatial patterns in the Hoh Xil region. The dominant one is that lake ice extends from one bank to the opposite side, followed by the lakes with ice extending around the shoreline to the center of the lakes. The lakes with ice cover firstly emerging in sub-lake then expanding to the whole lake were the least.

(3) The phenology of lake ice had changed dramatically during the period of 2000 to 2011 in the Hoh Xil region. The FUS and FUE time of lake ice showed an increasingly delaying trend and the rates were $0.73 \mathrm{~d} / \mathrm{a}$ and $0.34 \mathrm{~d} / \mathrm{a}$ respectively. However, the BUS and BUE time of lake ice presented an opposite trend at an average rate of $1.66 \mathrm{~d} / \mathrm{a}$ and $0.81 \mathrm{~d} / \mathrm{a}$, respectively. As a result, the CID and ID of lake ice were significantly reduced at an average rate of $2.21 \mathrm{~d} / \mathrm{a}$ and $1.91 \mathrm{~d} / \mathrm{a}$, respectively.

(4) The correlation analysis revealed that lake ice phenology depended on mean temperature, lake area, salinity and shape of the shoreline and each factor played a different role in the lake ice freeze-up and break-up cycle. Moreover, the local factors such as geological structure and geothermal energy could also affect the evolution of lake ice. Meanwhile, more attention should be paid to some scientific researches in the coming time. For example, the reduction of lake ice duration in the wide range of Hoh Xil region certainly breaks the balance of heat budget, how this variation affects the evaporation of lake water and regional climate, etc.

\section{References}

Barrie R B, Terry D P, Claude R D et al., 2006. Impacts of large-scale teleconnections on freshwater-ice break/freeze-up dates over Canada. Journal of Hydrology, 330: 340-353.

Benson B J, Magnuson J J, Jensen O P et al., 2012. Extreme events, trends, and variability in Northern Hemisphere lake-ice phenology (1855-2005). Climatic Change, 112: 299-323.

Che T, Li X, Jin R, 2009. Monitoring the frozen duration of Qinghai Lake using satellite passive microwave remote sensing low frequency data. Chinese Science Bulletin, 54: 2294-2299. (in Chinese)

Chen X Z, Wang G Y, Li W J et al., 1995. Lake ice and its remote sensing monitoring in the Tibetan Plateau. Journal of Glaciology and Geocryology, 17(3): 241-246. (in Chinese)

Choinski A, Kolendowicz L, Pociask K J et al., 2010. Changes in lake ice cover on the Morskie Oko Lake in Poland (1971-2007). Advances in Climate Change Research, 1(2): 71-75.

Deguay C R, Prowse T D, Bonsal B R et al., 2006. Recent trends in Canadian lake ice cover. Hydrology Process, 20: 781-801.

Ghanbari R N, Bravo H R, Magnuson J J et al., 2009. Coherence between lake ice cover, local climate and teleconnections. Journal of Hydrology, 374(3/4): 282-293.

Gould M, Jeffries M, 2005. Temperature variations in lake ice in central Alaska, USA. Annals of Glaciology, 40(1): 89-94.

Hall D K, Riggs G A, Salomonson V V et al., 2002.MODIS snow-cover products. Remote Sensing of Environment, 83: 181-194.

Hodgkins A G, James I C, Huntington T G, 2002. Historical changes in lake ice-out dates as indicators of climate change in New England, 1850-2000. International Journal of Climate, 22: 1819-1827.

$\mathrm{Hu}$ D S, 1992. Investigation and study on lake resources in Kekexili region. Arid Land Geography, 15(3): 50-58. (in Chinese)

Johnson S L, Stefan H G, 2006. Indicators of climate warming in Minnesota: Lake ice covers and snowmelt runoff. Climate Change, 75(4): 421-453.

Kropáček J, Maussion F, Chen F et al., 2013. Analysis of ice phenology of lakes on the Tibetan Plateau from 
MODIS data. The Cryosphere, 7: 287-301.

Latifovic R, Pouliot D, 2007. Analysis of climate change impacts on lake ice phenology in Canada using the historical satellite data record. Remote Sensing of Environment, 106: 492-507.

Lenormand F, Duguay C R, Gauthier R, 2002. Development of a historical ice database for the study of climate change in Canada. Hydrological Processes, 16(18): 3707-3722.

Livingstone D M, 1997. Break-up dates of alpine lakes as proxy data for local and regional mean surface air temperatures. Climatic Change, 37: 407-439.

Luo C G, Han F Q, Pang X P et al., 2010. Study on sublacustrine morphology of main lakes in Hoh Xil region. Journal of Salt lake Research, 18(1): 1-8. (in Chinese)

Marszelewski W, Skowron R, 2006. Ice cover as an indicator of winter air temperature changes: Case study of the Polish Lowland lakes. Hydrological Sciences Journal, 51(2): 336-349.

Ménard P, Duguay C R, Flato G M et al., 2002. Simulation of ice phenology on Great Slave Lake, Northwest Territories, Canada. Hydrology Process, 16: 3691-3706.

Palecki M A, Barry R G, 1986. Freeze-up and break-up of lakes as an index of temperature changes during the transition seasons: A case study for Finland. Journal of Applied Meteorology and Climatology, 25: 893-902.

Qin D H, 2012. Climate and Environment Change in China: 2012 the Comprehensive Volume. Beijing: China Meteorological Press. (in Chinese)

Qu B, Kang S C, Chen F et al., 2012. Lake ice and its effect factors in the Nam Co basin, Tibetan Plateau. Progressus Inquisitiones De Mutatione Climatis, 8(5): 327-333. (in Chinese)

Reed B, Budde M, Spencer P et al., 2009. Integration of MODIS-derived metrics to assess interannual variability in snowpack, lake ice, and NDVI in southwest Alaska. Remote Sensing of Environment, 113: 1443-1452.

Todd M C, Mackay A W, 2003. Large-scale climate controls on Lake Baikal ice cover. Journal of Climate, 16(19): 3186-3199.

Vaughan D G, Comiso J C, Allison I et al., 2013. Observations: Cryosphere. In: Stocker T F, Qin D, Plattner G K et al. ed. Climate Change 2013: The Physical Science Basis. Contribution of Working Group I to the Fifth Assessment Report of the Intergovernmental Panel on Climate Change. Cambridge: Cambridge University Press.

Wang J, Bai X, Hu H et al., 2012. Temporal and spatial variability of Great Lakes ice cover, 1973-2010. Journal of Climate, 25: 1318-1329.

Wang S M, Dou H S, 1998. Records of Lakes in China. Beijing: Science Press. (in Chinese)

Wei Q F, Ye Q H, 2010. Review of lake ice monitoring by remote sensing. Progress in Geography, 29(7): 803-810. (in Chinese)

Wu S H, Yin Y H, Zheng D et al., 2005. Climate change in the Tibetan Plateau during the last three decades. Acta Geographica Sinica, 60(1): 3-11. (in Chinese)

Yao X J, Liu S Y, Li L et al., 2014. Spatial-temporal characteristics of lake area variations in Hoh Xil region from 1970 to 2011. Journal of Geographical Sciences, 24(4): 689-702.

Yao X J, Liu S Y, Sun M P et al., 2012. Changes of Kusai Lake in Hoh Xil region and causes of its water overflowing. Acta Geographica Sinica, 67(5): 689-698. (in Chinese)

Zhang Z, Dong Z B, Yan C Z et al., 2015. Change of lake area in the southeastern part of China's Badain Jaran Sand Sea and its implications for recharge sources. Journal of Arid Land, 7(1): 1-9.

Zheng M P, Xiang J, Wei X J et al., 1989. Saline Lakes on the Qinghai-Xizang (Tibet) Plateau. Beijing: Science Press. (in Chinese) 